\title{
PENGARUH KEPEMIMPINAN DAN KEINOVATIFAN TERHADAP KINERJA PERUSAHAAN PADA PT. PELAYARAN NASIONAL BAHTERA BESTARI SHIPPING
}

\author{
Kwari Kristiani \\ Program Studi Magister Manajemen Universitas Tarumanagara \\ kwari_bbs@hotmail.co.id
}

\begin{abstract}
This study aims to determine the influence of Leadership and Innovativeness on Business Performance at PT. Bahtera Bestari Shipping. This research method using quantitative method. Data collection was done by distributing questionnaires to 100 employees of PT. Bahtera Bestari Shipping Shipping then data processed with SPSS program, after which the data is analyzed by using regression analysis. The results showed that there was an influence between Inovativeness and business performance of $69.2 \%$. For the Leadership variable itself does not have an impact on business performance due to a decrease in the variables. The results of the analysis show that the influence between leadership and innovation variables on business performance where the company must develop innovation to develop the company's performance in order to maintain the company in the era of globalization competition in the world of shipping so that the company is able to diversify at international level.
\end{abstract}

Keywords : Transformational Leadership, Transactional Leadership, Innovativeness, Business Performance

\section{PENDAHULUAN}

Indonesia merupakan negara kepulauan Indonesia sebagai negara kepulauan terbesar di dunia dengan jumlah pulau mencapai 17.508 pulau dengan bentangan laut yang sangat panjang yaitu 94.166 kilometer merupakan negara dengan garis pantai terpanjang keempat setelah Canada, Amerika dan Rusia. Dengan kondisi yang demikian, Indonesia memerlukan alat angkutan massal dalam jumlah besar untuk mendukung distribusi barang serta untuk memobilisasi penumpang. Tidak dapat dipungkiri bahwa sarana transportasi laut di negara kepulauan seperti Indonesia telah menjadi tulang punggung utama pergerakan distribusi barang dalam skala besar dengan menggunakan kapal laut

Dalam hal ini perusahaan dituntut mempertahankan kinerja perusahannya agar dapat bertahan dan terus meningkatkan inovasinya. Dalam perusahaan, bisnis bisa sukses dan tetap eksis serta bertahan apabila memiliki kemampuan kompetitif atau memiliki daya saing tinggi dan perusahaan dituntut untuk dapat bekerja secara efisien dan efektif sehingga mampu bersaing baik dalam kancah domestik maupun internasional. Persaingan yang semakin ketat menyebabkan perusahaan dituntut untuk mampu meningkatkan daya saing dalam rangka menjaga kelangsungan hidup perusahaan. Hampir di semua perusahaan mempunyai tujuan yaitu memaksimalkan keuntungan dan nilai bagi perusahaan, dan juga untuk meningkatkan kesejahteraan pemilik dan karyawan.

Dalam studi ini meneliti bagaimana pengaruh kepemimpinan dan keinovatifan memiliki efek yang sangat besar bagi kinerja perusahaan karena pemimpin memiliki pengaruh signifikan atas kebijakan perusahaan dan keinovatifan merupakan adalah efek penting pada lingkungan bisnis yang kompetitif. Kompetisi telah menjadi alat tekanan dalam bisnis diseluruh dunia..

Oleh karena peningkatan globalisasi dari perusahaan industri dan saling ketergantungan antar bangsa, kebutuhan untuk pemahaman yang lebih baik dari pengaruh 
kepemimpinan dan sebuah inovasi terhadap kinerja usaha belum pernah lebih besar. Situasi pemimpin dan yang akan memimpin harus menghadapi kompleksitas yang tinggi, perubahan yang konstan, dan kesulitan untuk menafsirkan. Menghadapi perubahan tersebut perusahaan harus mampu mengelola sumber daya yang dimiliki agar dapat membantu meningkatkan kinerja suatu perusahaan, yang pada akhirnya akan meningkatkan nilai perusahaan. Keinovatifan menjadi salah satu kata kunci untuk membantu organisasi menjadi lebih kompetitif. Dalam memaksimalkan kinerja usahanya sangatlah penting bagi perusahaan untuk dapat menyadai bahwa kepemimpinan dan keinovatifan ada hubungannya dengan kinerja perusahaan, karena kesesuaian antara keduanya dapat menentukan sebuah perusahaan dimasa depan. Setiap perusahaan memiliki pemimpin yang memiliki ciri khas dalam membawa perusahaannya untuk dapat maju dan bersaing.

Kepemimpinan dan keinovatifan menjadi salah satu kunci bagaimana pemilik perusahan mempertahankan dan mengembangkan kinerja perusahaannya. Salah satu upaya besar yang harus dilakukan perusahaan adalah mengoptimalkan sumber daya manusia yang dimiliki sebagai salah satu sumber daya perusahaan yang sangat penting jika tidak bisa mengatasi hal tersebut perusahaan akan dinyatakan pailit dikarenakan competitor yang semakin banyak didalam bidang pelayaran.

Kesuksesan merupakan buah dari kinerja perusahaan yang berkembang dan maju sehingga tidak lepas dari usaha pemimpin dalam mengarahkan perusahaannya untuk mengembangkan inovasi baru agar mencapai target pasar. Karena hal tersebut peneliti tertarik untuk meneliti perusahaan ini bagaimana perusahaan mempertahankan dan mengembangkan usahanya ditingkat persaingan globalisasi.

Dengan adanya latar belakang ini maka tujuan studi ini untuk mengetahui pengaruh kepemimpinan dan keinovatifan terhadap kinerja perusahaan pada PT. Pelayaran Nasional Bahtera Bestari Shipping.

\section{TUJUAN PENELITIAN}

Sesuai dengan rumusan masalah diatas, secara umum penelitian ini mempunyai tujuan untuk mengindentifikasi teori yang telah ada dalam menjelaskan mengenai pengaruh kepemimpinan dan keinovatifan terhadap kinerja perusahaaan pada PT. Pelayaran Nasional Bahtera Bestari Shipping. Secara khusus, penelitian ini bertujuan untuk menguji dan menganalisis pengaruh kepemimpinan dan keinovatifan terhadap kinerja perusahaan pada PT. Pelayaran Nasional Bahtera Bestari Shipping.

\section{TINJAUAN PUSTAKA}

KEPEMIMPINAN Perusahaan dapat di katakan juga sebagai suatu organisasi yang di dalamnya terdapat struktur kerja. Kepemimpinan yang di tampilkan di dalam organisasi secara umum juga di tampilkan di dalam organisasi di dalam perusahaan. Teori-teori kepemimpinan yang ada juga dapat di aplikasikan di dalam organisasi perusahaan. Namun yang menjadi focus utama adalah bagaimana kepemimpinan seorang pemimpin didalam perusahaan mampu menggerakan para karyawan untuk gigih dalam mencapai tujuan perusahaan. Kepemimpinan yang ditunjukan oleh pemimpin didalam perusahaan juga harus berorientasi pada kemajuan perusahaannya.

Kepemimpinan adalah sebuah keputusan dan lebih merupakan hasil dari proses perubahan karakter atau transformasi internal dalam diri seseorang. Kepemimpinan bukanlah jabatan atau gelar, melainkan sebuah kelahiran dari proses panjang perubahan dalam diri seseorang. Ketika seseorang menemukan visi dan misi hidupnya, ketika terjadi kedamaian dalam diri (inner peace) dan membentuk bangunan karakter yang kokoh, ketika setiap ucapan dan tindakannya mulai memberikan pengaruh kepada lingkungannya, dan ketika keberadaannya mendorong perubahan dalam organisasinya, pada saat itulah seseorang lahir 
menjadi pemimpin sejati. Jadi pemimpin bukan sekedar gelar atau jabatan yang diberikan dari luar melainkan sesuatu yang tumbuh dan berkembang dari dalam diri seseorang. Kepemimpinan lahir dari proses internal.

Menurut Sarros dan Butchatsky (1996), kepemimpinan didefinisikan sebagai perilaku terarah yang mempengaruhi orang lain untuk berkontribusi pada tujuan yang telah disepakati bersama untuk kepentingan individu dan juga organisasi atau kebaikan bersama.

Menurut Firestone (1996), kepemimpinan termasuk dalam posisi tertentu dan mencakup tugas dan fungsi, dibagi menjadi dua kategori sebagai fungsi kepemimpinan dalam transaksional dan fungsi kepemimpinan dalam transformasi. Dalam penelitian ini, fungsi kepemimpinan dalam transaksional telah dievaluasi sebagai dukungan dan struktur. Dalam beberapa tahun terakhir, gaya kepemimpinan transaksional dan transformasional telah diperiksa dan mendapat perhatian dalam studi ilmiah. Dimensi kepemimpinan dibagi menjadi dua yaitu :

1. Kepemimpinan Transformasional

Kepemimpinan transformasional didefinisikan sebagai kepemimpinan yang melibatkan perubahan dalam organisasi. Kepemimpinan ini juga didefinisikan sebagai kepemimpinan yang membutuhkan tindakan memotivasi para bawahan agar bersedia bekerja demi sasaran-sasaran tingkat tinggi yang dianggap melampaui kepentingan pribadinya. Popper dan Zakkai (1994) mendefinisikan kepemimpinan transformasional merupakan kepemimpinan yang proaktif. Proaktif di sini berarti pemimpin melihat kondisi saat ini sebagai batu loncatan untuk pencapaian tujuan di masa depan. Kepemimpinan transformasional juga merupakan kepemimpinan yang dapat diterapkan dengan karakteristik kharismatik, pengaruh idealis, motivasi inspirasional, stimulasi intelektual, serta konsiderasi individu.keterampilan kecakapan hidup baik untuk diri sendiri, berkelompok atau bermasyarakat yaitu berupa keterampilan dalam berhubungan dengan orang lain maupun keterampilan dalam mengatur dirinya sendiri agar mampu mengembangkan produktifitas kerja secara maksimal (Hartiti, 2013).

2. Kepemimpinan Transaksional

Kepemimpinan transaksional memungkinkan pemimpin memotivasi dan mempengaruhibawahan dengan cara mempertukarkan reward dengan kinerja tertentu. Artinya, dalam sebuah transaksi bawahan dijanjikan untuk diberi reward bila bawahan mampu menyelesaikan tugasnya sesuai dengan kesepakatan yang telah dibuat bersama.

Pada hubungan transaksional, pemimpin menjanjikan dan memberikan penghargaan kepada bawahannya yang berkinerja baik, serta mengancam dan mendisiplinkan bawahannya yang berkinerja buruk. Penghargaan yang dijanjikan atau terhindarnya dari hukuman itu mampu memotivasi bawahannya untuk meningkatkan kinerjanya. Hal ini tergantung pada apakah pemimpinnya mampu mengendalikan penghargaan dan hukuman tersebut, serta apakah bawahan menginginkan penghargaan atau takut terhadap hukuman tersebut (Bass, 1990).

KEINOVATIFAN Keinnovatifan menjadi perubah utama dalam proses difusi inovasi yang disponsori oleh agen perubahan. Pada negara berkembang keinovatifan dipandang sebagai salah satu indikator kesuksesan program-program pembangunan. Keinovatifan menunjukan perubahan tingkah laku yaitu tujuan akhir program difusi bukan hanya pikiran dan sikap.

Menurut Everett(1995), keinovatifan (Innovativeness) adalah sejauh mana individu atau unit adopsi lain relatif lebih awal dalam mengadopsi ide-ide baru dari anggota lain dari suatu sistem. Keinovatifan lebih menunjukkan perubahan perilaku yang nyata, yang menjadi tujuan utama dari sebagian besar program difusi, daripada hanya perubahan kognitif maupun sikap. Keinovatifan merupakan perilaku utama dala proses difusi. Menurut Rogers (1995), keinovatifan adalah tingkat yang berkenaan dengan seberapa lama 
seseorang/kelompok/sistem sosial lebih dahulu dalam mengadopsi ide-ide baru dari konsepkonsep difusi inovasi dibandingkan dengan yang lain.

KINERJA PERUSAHAAN Kinerja perusahaan adalah hasil dari kegiatan manajemen. Parameter yang sering digunakan untuk menilai kinerja suatu perusahaan yang dilakukan dengan menggunakan pendekatan di mana informasi keuangan diambil dari laporan keuangan atau laporan keuangan lainnya.

Menurut Rhoades (2002), Penilaian kinerja bertujuan untuk menentukan efektivitas operasi perusahaan. Hal ini dapat dilakukan dengan menggunakan metode atau pendekatan. Konsep kinerja menggambarkan bagaimana individu atau kelompok mencapai suatu kesimpulan untuk mencapai suatu tujuan. Kinerja adalah konsep yang ditunjukkan oleh karyawan utama organisasi saat memenuhi tugasnya. Inilah sebabnya mengapa kesuksesan organisasi secara langsung sesuai dengan kinerja karyawan mereka. Menurut Yildiz (2010), Kinerja bisnis adalah gambaran tingkat tugas atau sasaran usaha yang terpenuhi sesuai dengan hasil / kesimpulan yang diperoleh pada akhir bisnis perion

Kinerja perusahaan hanya dapat diukur dengan metode subjektif atau hanya metode objektif. Juga dapat dilihat dalam literatur bahwa metode subjektif dan objektif digunakan bersamaan untuk menghindari kedatangan setiap metode. Telah terbukti bahwa sementara profitabilitas, penjualan dan pangsa pasar merupakan kriteria yang paling banyak digunakan dalam metode subjektif ROA dan ROE adalah metode yang paling banyak digunakan dalam metode objektif (Yildiz dan Karakas). Meskipun berbagai metode pengukuran kinerja bisnis telah dikembangkan oleh para ilmuwan dan praktisi, namun tidak dapat dikatakan bahwa selalu ada metode yang valid.

\section{METODOLOGI PENELITIAN}

Penelitian dilakukan pada perusahaan pelayaran swasta yaitu PT. Pelayaran Nasional Bahtera Bestari Shipping. Sumber data yang digunakan dalam penelitian ini adalah data primer. Waktu penelitian dilakukan selama delapan bulan mulai dari bulan Agustus tahun 2017 sampai Maret tahun 2018. Populasi pada penelitian ini adalah karyawan yang bekerja di PT. Pelayaran Nasional Bahtera Bestari Shipping baik yang bekerja back office maupun out office diperoleh 100 orang karyawan sebagai sampel. Teknik pengumpulan data menggunakan kuisioner dengan skala likert dan metode kuantitatif ( data yang bisa diangkakan atau dikuantifikasikan ). Teknik analisis yang digunakan Analisis Regresi Linear Berganda.

\section{HASIL \& KESIMPULAN \\ Hasil Uji Asumsi Klasik.}

Uji Multikolinearitas berguna untuk mengetahui apakah model regresi ditemukan korelasi kuat antar variabel bebas ( independent ) Prasyarat yang harus terpenuhi adalah tidak adanya multikolinearitas dalam model refgresi. Multikolinearitas dapat diketahui dengan melihat nilai Variance Inflation Factor (VIF) pada model regresi. Jika besar VIF < 10, maka mencerminkan tidak ada multikoloneritas. Berdasarkan hasil multikolinearitas diketahui nilai VIF untuk transactional leadership sebesar 1,045, transformational leadership sebesar 1,074 dan innovativeness 1,029. Jadi, dapat disimpulkan bahwa tidak adanya multikolinearitas dalam model regresi yang digunakan, hal ini dikarenakan nilai $\mathrm{VIF}<10$.

Uji heteroskedatisitas dilakukan untuk mengetahui apakah dalam sebuah model regrsi terjadi heteroskedatisitas varian dari residual suatu pengamatan ke pengamatan lain. Peneliti menguji heteroskedastisitas yaitu Transactional Leadership, Transformational Leadership, dan Innovativeness terhadap Business Performance ditemukan titik-titik menyebar di atas dan di bawah angka 0 dari sumbu $\mathrm{Y}$, maka memiliki kesamaan varians atau tidak terjadi heteroskedastisitas. 
Uji normalitas berguna untuk mengetahui variabel bebas dan variabel terikat dalam penelitian ini keduanya berdistribusi normal, mendekati normal, atau tidak. Model regresi yang baik memiliki distribusi data normal atau mendekati normal. Uji normalitas pada penelitian ini menggunakan uji Kolmogorov-smirnov dan dikatakan normal jika nilai residual yang terdistribusi secara normal memiliki probabilitas siginifikasi lebih besar dari 0,05. Hasil uji normalitas menunjujan bahwa signifikasi sebesar 0,07 artinya nilai variabel tersebut secara keseluruhan berdistribusi normal.

Model Persamaan Regresi Model persamaan regresi berdasarkan tabel 1 dapat dituliskan sebagai berikut

$$
\mathrm{Y}=4,194 \mathrm{BP}-0,031 \mathrm{X} 1 \mathrm{a}-0,017 \mathrm{X} 1 \mathrm{~b}+0.692 \mathrm{X} 2
$$

Berdasarkan model persamaan tersebut, Berikut penjelasan mengenai persamaan regresi atas:

a. Apabila kepemimpinan transaksional, kepemimpinan transformasional dan keinovatifan terhadap $(X 1 \mathrm{a}, \mathrm{X} 1 \mathrm{~b}, \mathrm{X} 2)=0$, maka kinerja perusahaan $(\mathrm{Y})=4,194$.

b. Apabila terjadi perubahan pada variabel kepemimpinan transaksional (X1a) sebesar satu satuan dan variabel lainya dianggap konstan, maka kinerja perusahaan (Y) akan menurun sebesar 0,031 satuan.

c. Apabila terjadi perubahan pada variabel kepemimpinan transformasional (X1b) sebesar satu satuan dan variabel lainya dianggap konstan, maka kinerja perusahaan (Y) akan menurun sebesar 0,017 satuan.

d. Apabila terjadi perubahan pada variabel keinovatifan (X2) sebesar satu satuan dan variabel lainya dianggap konstan, maka kinerja perusahaan (Y) akan meningkat sebesar 0,692 satuan.

Dari persamaan di atas dapat disimpulkan bahwa nilai koefisien regresi (b) yang paling besar adalah nilai poin D pada keinovatifan yaitu sebesar 0,692 satuan.

\section{Hasil Pengujian Analisa Regresi ( Uji t )}

Hasil analisis regresi berganda dapat dilihat pada tabel 1 berikut.

Tabel 1. Analisis Regresi Ganda Kepemimpinan Transaksional, Kepemimpinan
transformasional
Kinerja Perusahaan
Coefficients

Berdasarkan tabel 1 di atas dapat diketahui nilai thitung dari setiap variabel. 
a. Pengaruh transactional leadership terhadap business performance Berdasarkan tabel dapat diperoleh nilai $t_{\text {hitung }}$ sebesar $-0,987$ dengan nilai Sig sebesar 0,326. Hal ini menunjukkan bahwa nilai $t_{\text {hitung }}$ lebih kecil dari pada nilai $t_{\text {tabel }}$ 1,966 dan nilai Sig lebih besar dari pada 0,05. Dengan demikian $\mathrm{H}_{0}$ diterima dan $\mathrm{H}_{\mathrm{a}}$ ditolak. Artinya variabel transactional leadership tidak mempunyai pengaruh yang siginifikan terhadap business performance.

b. Pengaruh transformational leadership terhadap business performance Berdasarkan tabel dapat diperoleh nilai $t_{\text {hitung }}$ sebesar $-0,767$ dengan nilai Sig sebesar 0,445. Hal ini menunjukkan bahwa nilai thitung lebih kecil dari pada nilai $t_{\text {tabel }} 1,966$ dan nilai Sig lebih besar daripada 0,05. Dengan demikian $\mathrm{H}_{0}$ diterima dan $\mathrm{H}_{\mathrm{a}}$ ditolak. Artinya variabel transformational leadership tidak mempunyai pengaruh yang siginifikan terhadap business performance.

c. Pengaruh innovativeness terhadap business performance Berdasarkan tabel dapat diperoleh nilai thitung sebesar 29,835 dengan nilai Sig sebesar 0,000. Hal ini menunjukkan bahwa nilai $t_{\text {hitung }}$ lebih besar dari pada nilai $t_{\text {tabel }}$ 1,966 dan nilai Sig lebih kecil daripada 0,05. Dengan demikian $\mathrm{H}_{0}$ ditolak dan $\mathrm{H}_{\mathrm{a}}$ diterima. Artinya variabel innovativeness mempunyai pengaruh yang siginifikan terhadap business performance.

Hasil Analisis Deteminasi ( $\mathbf{R}^{\mathbf{2}}$ ) Pada tabel diatas, dijelaskan besarnya nilai korelasi atau hubungan $\left(\mathrm{R}^{2}\right)$ antara Transactional Leadership, Transformational Leadership, dan Innovativeness terhadap Business Performance sebesar 0,903 dan penjelasan besarnya presentase pengaruh varibel Transactional Leadership, Transformational Leadership, dan Innovativeness terhadap Business Performance yang disebut koefisien determinasi $\left(\mathrm{R}^{2}\right)$ pada model ini sebesar $90,3 \%$, dan sisanya dipengaruhi oleh variabel lain sebesar $9,7 \%$.

Hasil Uji F uji F dilakukan untuk melihat pengaruh variabel-variabel independen secara keseluruhan terhadap variabel dependen. Untuk regresi linear ganda dilakukan pengujian terhadap koefisien regresi secara bersama-sama, yakni melihat pengaruh dari seluruh variabel independen terhadap dependen. Uji F pada penelitian ini dilakukan pada table 1 yaitu regresi Transactional Leadership, Transformational Leadership, dan Innovativeness terhadap Business Performance

Dari tabel 1 di atas diperoleh tingkat signifikansi sebesar 0,000 dimana angka tersebut lebih kecil dari pada 0,05 , ini berarti $\mathrm{H}_{0}$ ditolak. Maka dapat disimpulkan bahwa paling sedikit terdapat satu variabel independen yang mempengaruhi Business Performance

\section{PENUTUP}

Kesimpulan (1)Tidak terdapat pengaruh transactional leadership terhadap business performance. (2) Tidak terdapat pengaruh terhadap transformational leadership terhadap business performance. (3) Terdapat pengaruh innovativness terhadap business performance. (4) Terdapat pengaruh transactional leadership, transformational leadership, dan innovativeness terhadap business performance.

Saran Terkait dengan hasil penelitian ini, terdapat beberapa saran yang sekiranya dapat bermanfaat untuk perusahaan dan untuk penelitian selanjutnya, yaitu sebagai berikut : (1)Saran Teoritis : a. Untuk pengembangan ilmu, penelitian selanjutnya diharapkan mampu memperhatikan faktor-faktor atau penyebab lain dari business performance. Menggunakan lebih dari tiga independent variabel diharapkan mampu membuat hasil yang lebih baik dibanding hasil pada penelitian ini. (2)Saran bagi penelitian lebih lanjut: a. Penelitian lebih lanjut dapat dilakukan untuk mengukur tingkat business performance perusahaan dalam hubungannya dengan implementasi leadership. b. Penelitian ini hanya mengambil responden karyawan didalam perusahaan pelayaran satu saja. Peneliti selanjutnya sebaiknya mengambil 
responden beberapa perusahaan pelayaran lainnya sehingga populasi lebih beragam lagi dan hasil penelitian berikutnya bermanfaat bagi perusahaan pelayaran di Indonesia.(3)Saran Managerial : a. Diharapkan perusahaan terlebih dahulu menganalis faktor-faktor yang mempengaruhi berkembangnya perusahaan pelayaran di Indonesia sehingga mampu mengekspansi sampai jenjang Internasional bukan hanya di ASEAN saja. b. Peneliti menyarankan bahwa perusahaan harus lebih memperhatikan setiap detail proses inovasi yang akan dijalankan serta risk yang akan dihadapi sebelum melakukan proses inovasi.

\section{DAFTAR PUSTAKA}

Aragon-Correa, J.A, Garcia-Morales, V.J \& Cordon-Poza, E (2007), Leadership and Organizational Learning's Role on Innovation and Performance : Lesson from Spain, Industial Marketing Management, 36:349-359

Bass,B.M. \& Avilio, B.J, Beyond (1994), The Implication of transactional and transformational Leadership : 1994 and. Journal of European Industrial training. Vol $: 14,21-27$.

Garcia-Morales Victor J., Francisco Javier Llore'ns-Montes and Antonio J. Verdu' -Jover (2014) The Effects of Transformational Leadership on Organizational Performance through Knowledge and Innovation British Journal of Management, Vol. 19, 299-319 (2008)

Ghozali, Imam. (2001). “Aplikasi Analisis Multivariate dengan Program SPSS”. Semarang: Badan Penerbit Universitas Diponegoro.

Kartono (2006), Pemimpin dan Kepemimpinan, Jakarta : PT. Rajagrafindo Persada.

Kuncoro, Mudrajad. 2003. Metode Riset untuk Bisnis \& Ekonomi. Jakarta: Erlangga.

Lin Chien-Huang, Ching-Huai Peng, Danny T. Kao, (2008), The innovativeness effect of market orientation and learning orientation on business performance, International Journal of Manpower, Vol. 29 Issue: 8, 752-772

Malhotra, Naresh K. (2004). Marketing Research: An Applied Orientation, Pearson education, inc., Fifth Edition, New Jersey, USA.

Margono, Drs. S. Margono (2004) Metodologi Pendidikan Penelitian. Jakarta: Rineka Cipta

Priyatno, Duwi, 2011 Mandiri Belajar Analisis Data Dengan SPSS, Yogyakarta, Mediakom.

Robert E. Overstreet, Joe B. Hanna, Terry A. Byrd, Casey G. Cegielski, Benjamin T. Hazen, (2013), Leadership style and organizational innovativeness drive motor carriers toward sustained performance, The International Journal of Logistics Management, Vol. 24 Issue: 2, 247-270

Roslan Abdul Aziz, Mohd Hussin Abdullah, Anas Tajudin, (2013), The Effect of Leadership Styles on the Business Performance of SMEs in Malaysia, Indexing and Abstracting: Ulrich's - Global Serials Directory, Vol. 2, No.2 , 45-52

Sekaran, Uma. (2003). Metodologi Penelitian Untuk Bisnis. Jakarta: Salemba 4

Santoso, Singgih. (2001). Mengolah Data Statistik Secara Profesional. PT. Alex Media Komputindo. Jakarta.

Sebahattin Yildiz, Faruk Bastrurk (2014), The Effec of Leadership and Innovativeness on Busines Performance, Sosial and Behavioral Sciences, 150 : 785 - 793

Sugiyono, (2009), Metode Penelitian Kuantitatif Kualitatif dan R\&D. Bandung

Sugiyono,(2014),Metode Penelitian Pendidikan Pendekatan Kuantitatif, Kualitatif Dan R\&D. Bandung: Alfabeta. 


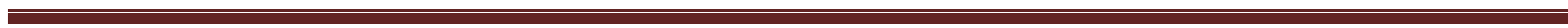
$\cdot$ 